Research Article

\title{
Phenylethanol Glycosides Protect Myocardial Hypertrophy Induced by Abdominal Aortic Constriction via ECE-1 Demethylation Inhibition and PI3K/PKB/eNOS Pathway Enhancement
}

\author{
Qiong-Ling Fan,, Jia-Wei Wang, ${ }^{1}$ Shi-Lei Zhang, ${ }^{2}$ Tao Liu, ${ }^{2}$ Jun Zhao $\mathbb{D}^{3},{ }^{3}$ \\ and Shu-Ping You $\mathbb{D}^{1}$ \\ ${ }^{1}$ Department of Nursing, Xinjiang Medical University, Urumqi 830011, China \\ ${ }^{2}$ Department of Public Health, Xinjiang Medical University, Urumqi 830011, China \\ ${ }^{3}$ Key Laboratory for Uighur Medicine, Institute of Materia Medica of Xinjiang, Urumqi 830004, China
}

Correspondence should be addressed to Shu-Ping You; youshupin@163.com

Received 15 January 2020; Accepted 13 May 2020; Published 9 June 2020

Academic Editor: Giuseppe Caminiti

Copyright () 2020 Qiong-Ling Fan et al. This is an open access article distributed under the Creative Commons Attribution License, which permits unrestricted use, distribution, and reproduction in any medium, provided the original work is properly cited.

\begin{abstract}
Phenylethanol glycosides (CPhGs) are the core material basis of pharmacological activity in Cistanche tubulosa and have a variety of pharmacological effects. However, it is unclear whether $\mathrm{CPhGs}$ have an ameliorative effect on pressure overload-induced myocardial hypertrophy. In this study, male SD rats weighing $(200 \pm 20)$ g were established cardiac hypertrophy models by abdominal aortic coarctation (AAC). After operation, the rats were gavaged with corresponding medicine for 6 weeks (CPhGs 125,250 , and $500 \mathrm{mg} / \mathrm{kg} / \mathrm{d}$ and valsartan $8.3 \mathrm{mg} / \mathrm{kg} / \mathrm{d}$ ). Echocardiography, heart weight index (HWI), cross-sectional area of cardiomyocytes (CSCA), fibrosis area, plasma endothelin 1(ET-1), and proinflammatory factors levels were detected. Our results showed that different CPhGs dosage decreased left ventricular posterior wall thickness (LVPWT), left ventricular end-diastolic diameter (LVED), HWI, CSCA, fibrosis area, ET-1, proinflammatory factors, arterial natriuretic peptide (ANP), brain natriuretic peptide (BNP), endothelin converting enzyme 1(ECE-1) mRNA levels, cyclooxygenase 2 (COX-2), high mobility group box 1 (HMGB-1) protein levels, and ECE-1 demethylation level while increasing left ventricular ejection fractions (LVEF), left ventricular fractional shortening (LVFS), phosphorylated phosphatidylinositol 3-kinase (p-PI3K), phosphorylated protein kinase B (p-PKB), and phosphorylated endothelial nitric oxide synthetase (p-eNOS). The indexes of CPhGs 250 and $500 \mathrm{mg} / \mathrm{kg}$ group were significantly different from AAC group; compared with valsartan group (AV), the indexes of CPhGs $500 \mathrm{mg} / \mathrm{kg}$ group were not significantly different. In conclusion, CPhGs ameliorated myocardial hypertrophy rats by AAC, which may be related to ECE1 demethylation inhibition and PI3K/PKB/eNOS enhancement.
\end{abstract}

\section{Introduction}

Myocardial hypertrophy is a common adaptive response to pressure overload in hypertensive patients [1]. But with the aggravation of myocardial hypertrophy, the demand for myocardial blood supply increases, and the decrease of coronary blood flow reserve leads to myocardial injury. The development of myocardial hypertrophy is known to increase the morbidity and mortality of cardiovascular diseases
[2-4]. Since hypertension is the main cause of myocardial hypertrophy, the current treatment of myocardial hypertrophy is mainly based on antihypertensive drugs, such as thiazine diuretics, calcium channel blockers, and angiotensin-converting enzyme inhibitors $[5,6]$. However, the electrolyte disturbance, postural hypotension, dry cough, and other adverse reactions caused by taking these drugs remain potential risks for patients. Hence, there is an urgent need to find safer and more effective drugs. 
Cistanche tubulosa, a precious traditional Chinese herb medicine, is widely grown in Xinjiang, China. It has a variety of benefits to the consumer such as strengthening immunity, tonifying kidney impotence, improving intelligence, antioxidation, antiaging, protecting liver, and lowering blood pressure [7]. The plant contains phenylethanol glycosides (CPhGs), oleoterpenes, and polysaccharides. CPhGs are one of the effective substances contained in Cistanche. Their main components are echinosides and moleniosides (molecular structure diagrams are shown in Figure 1). [8]. In in vivo and in vitro studies, CPhGs have been proven to be effective in the preventing and treating of ischemic heart disease $[9,10]$. Myocardial ischemia is also a critical pathological process of hypertrophy, but it is unclear whether the substance has a protective effect on hypertrophy.

Xinjiang Kazakh people suffer from high incidence of essential hypertension (EH) due to long-term consumption of salty milk tea $[11,12]$. In the previous study, we used methylation microarray to screen the abnormal methylation sites in the blood samples of Kazakh EH patients and normal people, showing that the demethylation level of endothelin converting enzyme 1 (ECE-1) was positively correlated with $\mathrm{EH}$ [13]. In previous pathway analysis, it was found that ECE-1 was involved in the phosphatidylinositol 3-kinase/ protein kinase $\mathrm{B} /$ endothelial nitric oxide synthase (PI3K/ $\mathrm{PKB} / \mathrm{eNOS}$ ) pathway [13]. PI3K/PKB/eNOS is an important pathway in the formation of myocardial hypertrophy and the downstream pathway of ET-1 [14-16]. A prior study has shown that CPhGs liposome could inhibit the proliferation of hepatic stellate cells by regulating $\mathrm{PI} 3 \mathrm{~K} / \mathrm{PKB}$ pathway [17]. Therefore, we hypothesised that CPhGs may play a protective role in human body by influencing ECE-1 and the $\mathrm{PI} 3 \mathrm{~K} / \mathrm{PKB} / \mathrm{eNOS}$ pathway.

Hence, we investigated the possible protective effect of CPhGs on myocardial hypertrophy and its effect on ECE-1 demethylation and PI3K/PKB/eNOS pathway with pressure overload myocardial hypertrophy in rats by abdominal aortic coarctation (AAC).

\section{Materials and Methods}

2.1. Animals. 70 male SPF SD rats weighed $200 \pm 20 \mathrm{~g}$ (10 per group) were provided by Experimental Animal Centre of Xinjiang Medical University (Urumqi, China). Animal production license number was SYXK(XIN)2016-0003 and certificate number was SCXK(XIN)2016-002. The study was approved by the Animal Ethnics Committee of the First Affiliated Hospital of Xinjiang Medical University (approval number 20180223-183). They were maintained with free access to water and food in plastic cages and kept in a $12 \mathrm{~h}$ light/dark cycle at a temperature of $22 \pm 2^{\circ} \mathrm{C}$ and humidity of $45-55 \%$ in our Experimental Animal Centre.

2.2. Materials. CPhGs, whose content of echinacea was more than $40 \%$ and acteoside was more than $16 \%$, were purchased from Hetian Di Chen Medical Biotechnology Co., Ltd. Valsartan was purchased from Beijing Novartis Pharma Co., Ltd. Carboxymethylcellulose sodium (CMC-Na) was provided by Xian Zhengtian Pharmaceutical Accessories Co., Ltd. And CPhGs were dissolved in 0.5\% CMC-Na.

2.3. Abdominal Aortic Coarctation (AAC). After anesthetized by $2.5 \%$ pentobarbital sodium $(2.5 \mathrm{ml} / \mathrm{kg}$ ) (Merck, Darmstadt City, Hessen, Germany), the rats were shaved and kept warm on heating pads. Then the abdominal cavity of the rat was opened for $2 \mathrm{~cm}$ in the middle of the abdomen in a sterile environment, the abdominal viscera were pushed to the right side, and the abdominal aorta was fully exposed at $0.5 \mathrm{~cm}$ above the right renal artery. Number 8 needle was ligated with number 2 wire in parallel to the abdominal cavity being sutured [18]. Abdominal aortas of rats in sham group were separated without ligation and there was no control group for the surgery. The day after the operation, AC $125 \mathrm{mg} / \mathrm{kg}$, AC $250 \mathrm{mg} / \mathrm{kg}$, and AC $500 \mathrm{mg} / \mathrm{kg}$ were fed with CPhGs by gavage; AV group were fed with valsartan by gavage; and control group, AAC group, and sham group were not fed with CPhGs or valsartan, once a day for 42 consecutive days. Drug dose was set on the basis of previous reference and preliminary experiment [8].

2.4. Echocardiography. Six weeks after AAC, the rats were anesthetized with $2.5 \%$ pentobarbital sodium and performed the echocardiography (Philips HD11 XE, Amsterdam, Netherlands). LVPWT, LVED, LVEF, and LVFS were measured four times to calculate the averages as the final indicators.

2.5. Heart Weight Index (HWI). After echocardiography, the rats were executed by collecting blood from the abdominal aorta. The hearts of rats were removed from chest and weighed after being washed by normal saline $\left(4^{\circ} \mathrm{C}\right)$ for 3 times and drained with clean filter paper. The HWI was calculated through the following formula:

$$
\text { HWI }=\frac{\text { heart weight }}{\text { body weight }} \text {. }
$$

2.6. Hematoxylin-Eosin and Masson Staining. The myocardium from left ventricular was fixed by $4 \%$ paraformaldehyde embedded in paraffin, crosscut with a section thickness of $4 \mu \mathrm{m}$, dried in an oven at $60^{\circ} \mathrm{C}$ for 2 hours, and then stained with hematoxylin-eosin or masson (Solaibio, Beijing, China). The structure of the myocardium was observed with an inverted phase contrast microscope (Leica, Frankfurt, Germany). Image $J$ software was used to calculate the CSAC and fibrosis area.

2.7. Enzyme Linked Immune Sorbent Assay (ELISA). Abdominal aortic blood was extracted from rats and placed in an anticoagulation tube for $2 \mathrm{~h}$ at room temperature and then centrifuged at $3000 \mathrm{r} / \mathrm{min}$ speed. The supernatant was absorbed with pipettes (Eppendorf, Hamburg, Germany) and stored at $-80^{\circ} \mathrm{C}$ for testing. Plasma ET-1, interleukin $1 \beta$ (IL-1 $\beta$ ), interleukin 6 (IL-6), tumor necrosis factor $\alpha$ 


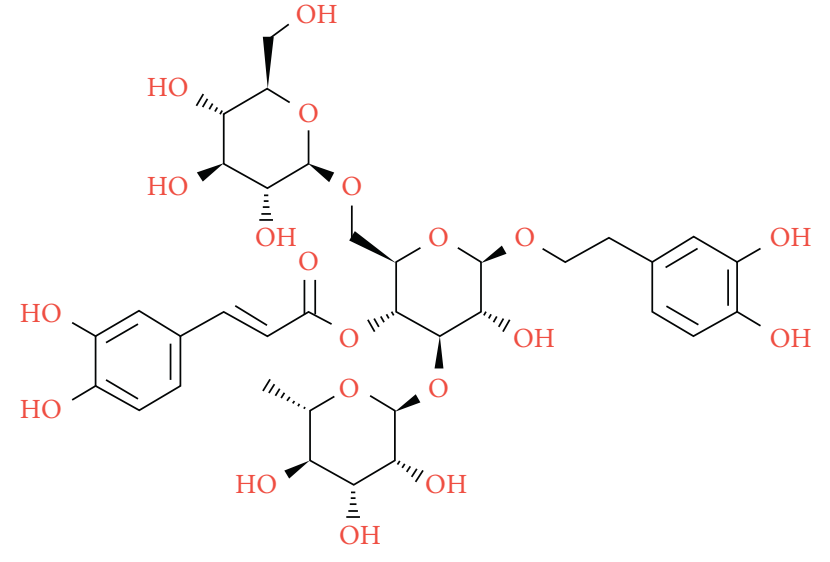

(a)

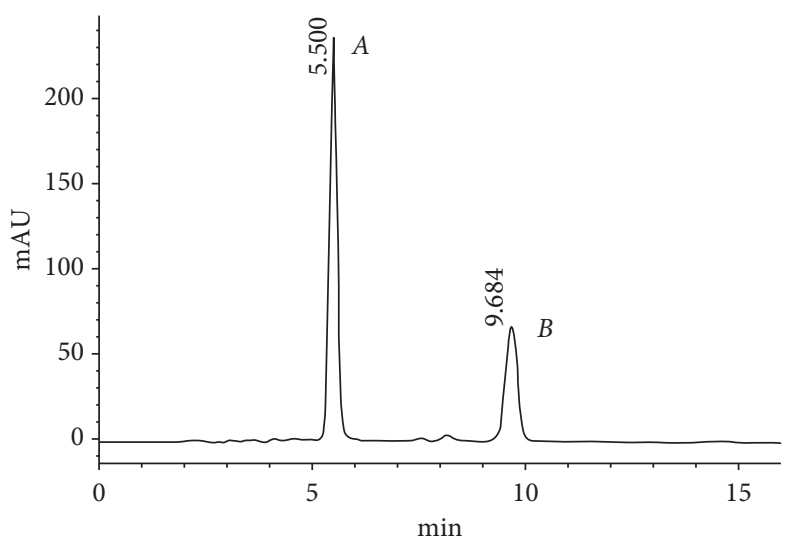

(c)<smiles>C[C@@H]1O[C@@H](O[C@H]2[C@H](O)[C@@H](OCCc3ccc(O)c(O)c3)O[C@@H](CO)[C@@H]2OC(=O)/C=C/c2ccc(O)c(O)c2)[C@H](O)[C@@H](O)[C@@H]1O</smiles>

(b)

FIgUre 1: (a) Echinacoside and (b) acteoside. (c) HPLC analysis of CPhGs.

(TNF- $\alpha$ ) (Bioss, Beijing, China), and cyclooxygenase 1 (COX-1) (Cusabio, Wuhan, China) levels of rats were detected according to ELISA kit instructions.

2.8. Methylation-Specific PCR. DNA was extracted from left ventricular myocardial tissue of rats by DNA extraction kit (Tiangen Biotech, Beijing, China). The absorption value (A value) was equal to OD260/OD280 (1.8 1.9). $20 \mu \mathrm{l}$ genomic DNA (500 pg-1 $\mu \mathrm{g}$ ) was modified with sulfurous acid by Methylation-Gold Kit (ZYMO, Orange County, CA, USA). The MSP reaction system was $25 \mu \mathrm{L}$, including $3.0 \mu \mathrm{L}$ of sulfite modified DNA template, $2.5 \mu \mathrm{L}$ of $10 \times$ buffer, $2.5 \mu \mathrm{L}$ of $2.5 \mathrm{~mm}$ dNTPs, $1.0 \mu \mathrm{L}$ of $10 \mu \mathrm{m}$ primer, $0.1 \mu \mathrm{L}$ of hotstar Taq DNA polymerase (TAKARA Biotechnology), and $14.9 \mu \mathrm{L}$ of $\mathrm{ddH}_{2} \mathrm{O}$. There were 45 cycles in total: denaturation at $95^{\circ} \mathrm{C}$, annealing at $55^{\circ} \mathrm{C}$, and extension at $72^{\circ} \mathrm{C}$ for $30 \mathrm{~s}$. After PCR, $5 \mu \mathrm{L}$ product was separated by $2 \%$ agarose gel electrophoresis. The DNA was treated by M. Sssl methyltransferase (New England Biolabs, Ipswich, MA, USA) was used as the positive control of methylation, and the DNA of normal control group was used as the positive control of demethylation. Finally, the agarose gel was photographed and analyzed by Bio-Rad gel imaging system. The demethylation level was calculated through the following formula:

$$
\text { Demethylation level }=\frac{\text { demethylated OD value }}{(\text { methylated OD value }+ \text { demethylated OD value })} \times 100 \%
$$

All primers designed in Methprimer (Applied Biosystems, MA, USA) and synthesized by Sangon Biotech (Shanghai, China) are listed in Table 1.

2.9. Quantitative Real-Time PCR. Total RNA was extracted from $50 \mathrm{mg}$ left ventricular myocardial tissue by trizol
(Thermo Scientific Inc., MA, US). The concentration and purity of RNA were detected by ultraviolet spectrophotometer with the standard of OD260/OD280 ratio of 1.8-2.0. After quantification, the RNA was reverse-transcribed into cDNA by RevertAid First Strand cDNA Synthesis Kit (Thermo Scientific, Inc.). The TB Green ${ }^{\mathrm{TM}}$ Premix Ex Taq ${ }^{\mathrm{TM}}$ 
TABLE 1: The primer sequences of ECE-1 used for methylation-specific PCR.

\begin{tabular}{lcc}
\hline Gene & Forward primer $\left(5^{\prime}-3^{\prime}\right)$ & Reverse primer $\left(3^{\prime}-5^{\prime}\right)$ \\
\hline Methylation primer $(\mathrm{M})$ & GGCGTTAGGTAGGAGATAAAGGTC & TCTAACTACCCCGAATACCGATAA \\
Demethylation primer $(\mathrm{U})$ & GTAGGTGTTAGGTAGGAGATAAAGGTTG & ACTCTAACTACCCCAAATACCAATAAA \\
\hline
\end{tabular}

II; were provided by Takara (Kyoto, Japan). qRT-PCR was performed by ABI QuantStudio ${ }^{\mathrm{TM}} 6$ Flex Real-Time PCR system (Applied Biosystems, Foster City, CA, USA). Baseline value and threshold value were set after completion, and the circulating threshold $\left(C_{\mathrm{T}}\right)$ was taken to analyze the relative expression level of the target gene by $2^{-\triangle \triangle C}$ T method. Primer sequences were synthesized by Sangon Biotech (Shanghai, China). All Primers used are listed in Table 2.

2.10. Western Blot. Proteins were extracted from left ventricular myocardium with RiPA Buffer (Thermo Scientific) and protease inhibitor was added. Protein concentration was determined by BCA method (Solarbio, Beijing, China). Proteins were taken at $50 \mu \mathrm{g}$ and denatured at $100^{\circ} \mathrm{C}$ for 5 mins. Proteins were separated by sodium dodecyl sulfate polyacrylamide gel electrophoresis (SDS-PAGE, Beyotime, Shanghai, China) and then transferred to a polyvinylidene fluoride (PVDF) membrane by electrophoretic equipment (Bio-Rad, CA, USA). After being blocked with 3\% BSA for 2 hours at room temperature, the membranes were incubated with anti-PI3K antibody, anti-phospho-PI3K antibody, antieNOS antibody, anti-phospho-eNOS (1:1000, Bioss, Beijing, China), anti-COX-2 antibody, anti-HMGB-1 antibody (1: 1000, Proteintech, Chicago, IL, USA), and anti-ECE-1 antibody (1:2000, Signalway Antibody, College Park, MD, USA), primary antibodies overnight at $4^{\circ} \mathrm{C}$. Next day, after being washed with TBST for 3 times, the membranes were incubated with HRP-labeled goat anti-rabbit IgG (1:25000, $1 \mathrm{~h}$, Zhongshanjinqiao, Shanghai, China) at room temperature. After being washed with TBST for 3 times, the membranes were visualized by Pierce ${ }^{\mathrm{TM}}$ ECL Western Blotting Substrate and imaged using FluorChem E Imaging System (Protein Simple, USA), which were normalized to $\beta$-actin as an internal control.

2.11. Statistical Analysis. The data were expressed as mean \pm standard deviation and analyzed by one-way ANOVA test using IBM SPSS Statistics 25.0 software (Chicago, IL, USA) and GraphPad software (San Diego, CA, USA). A value of $P<0.05$ was considered to be statistically significant.

\section{Results}

3.1. CPhGs Improved Cardiac Function in Rats after AAC. The rats received gavage from the day after AAC. The positive control group (AV) was given gavage with valsartan $8.3 \mathrm{mg} / \mathrm{kg} / \mathrm{d}$, and the CPhGs group (AC) was given gavage with CPhGs 125, 250, and $500 \mathrm{mg} / \mathrm{kg} / \mathrm{d}$, respectively. After six weeks' continuous dosing, the rats were performed echocardiography under $2.5 \%$ sodium pentobarbital anesthesia. Two rats died after AAC: one in model group died on the third day after AAC from pulmonary edema; another one in AC $500 \mathrm{mg} / \mathrm{kg}$ died the day after surgery suspected to be caused by surgical stress. As shown in Figure 2, compared with sham group, LVED, LVEF, and LVFS in AAC group were decreased significantly but LVPWT in AAC group was increased significantly. Compared with AAC group, LVED, LVEF, and LVFS were increased and LVPWT was decreased to varying degrees in each AC dose group; for LVPWT, significant change was not found in AC $125 \mathrm{mg} / \mathrm{kg}$ group but was found in AC 250 and $500 \mathrm{mg} / \mathrm{kg}$ groups. Compared with AV group, the LVPWT and LVED in AC $125 \mathrm{mg} / \mathrm{kg}$ group were observed significant difference, while LVPWT, LVED, LVFS, and LVFS in AC 250 and $500 \mathrm{mg} / \mathrm{kg}$ groups were not.

3.2. CPhGs Decreased HWI, CSAC, and Fibrosis Area in Rats after $A A C$. Then we weighed the heart of each rat to calculate the HWI and took the myocardial tissue for HE and masson staining to observe the changes of the cross-sectional area (CSAC) and fibrosis area in cardiomyocytes. As shown in Figures 3(a), 3(d), and 3(e), compared with sham group, the heart weight (HW) and HWI in AAC group were reduced significantly; compared with AAC group, HW and HWI in AC250 and $500 \mathrm{mg} / \mathrm{kg}$ groups were reduced significantly; compared with AV group, HW and HWI were increased significantly in AC $125 \mathrm{mg} / \mathrm{kg}$ group but were not in AC 250 and $500 \mathrm{mg} / \mathrm{kg}$ groups. In Figures 3(b) and 3(f), compared with sham group, the masson staining results showed that the fibrosis area in AAC group was increased significantly. For fibrosis area, significant decreasing was found in AC 125, 250, and $500 \mathrm{mg} / \mathrm{kg}$ groups when compared to AAC group, while significant increasing in AC 125 and $250 \mathrm{mg} / \mathrm{kg}$ groups and significant decreasing in $\mathrm{AC}$ $500 \mathrm{mg} / \mathrm{kg}$ group were found when compared to AV group. In Figures 3(c) and 3(g), the HE staining results showed that CSAC in AAC group was increased significantly in comparison with that in the sham group; compared with AAC group, CSAC in AC 250 and $500 \mathrm{mg} / \mathrm{kg}$ groups was reduced significantly; compared with that in AV group, however, CSAC was increased significantly in AC 125 and $250 \mathrm{mg} / \mathrm{kg}$ groups, and no significant difference was found in the $\mathrm{AC}$ $500 \mathrm{mg} / \mathrm{kg}$ group.

3.3. CPhGs Reduced mRNA Levels of Myocardial Hypertrophy Genes in Myocardial Tissue of Rats after AAC. ANP, BNP, and myosin heavy chain $\beta$ ( $\beta$-MHC) are important cardiac hypertrophy factors $[19,20]$. We detected the relative expression levels of these three cardiac hypertrophy genes in the myocardial tissues. As shown in Figure 4, compared with sham group, the relative expression levels of ANP, BNP, and $\beta$-MHC mRNA in AAC group were increased significantly; however, compared with AAC group, the relative expression levels of the three myocardial hypertrophy genes in AC 250 
TABLE 2: The primer sequences used for real-time PCR assay.

\begin{tabular}{lrc}
\hline Genes & Forward primer $\left(5^{\prime}-3^{\prime}\right)$ & Reverse primer $\left(3^{\prime}-5^{\prime}\right)$ \\
\hline ANP & GAGAGCGGACTAGGCTGCAA & TCAGTGGCAAlGCGACCAA \\
BNP & CGGATTGGCGCAGTCAGTCG & AGAGCCGCAGGCAGAGTCAG \\
$\beta$-MHC & GTGCCAATGACGACCTGAAGGAG \\
ECE- 1 & TCATCGGCTCACTCTCCAACTCC & CTGGTTGATGAGGCTGGTGTTCTG \\
$\beta$-Actin & TGTCACCAACTGGGAGGATA & CCTTCTTCCACCTGTGTTCTCTGC \\
\hline
\end{tabular}

RNA expression levels were measured by SYBR on 7500 Real-Time PCR System (Applied Biosystems, USA). Each experiment was conducted in triplicate.

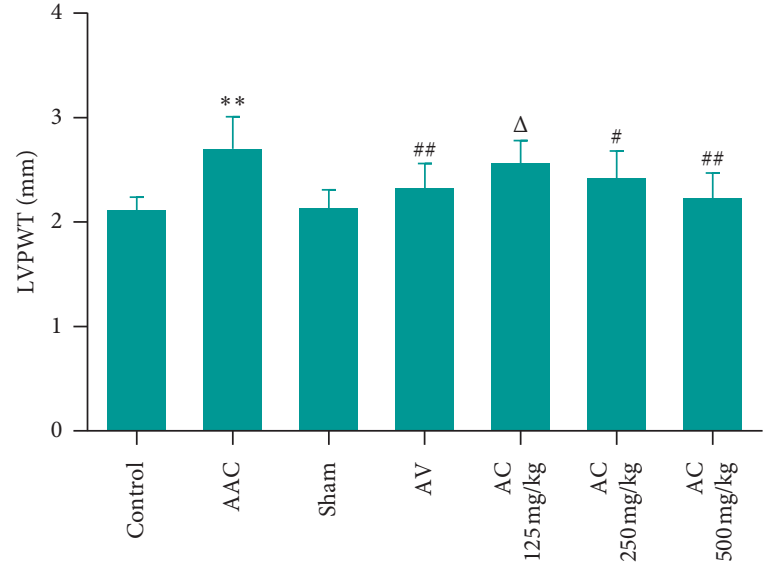

(a)

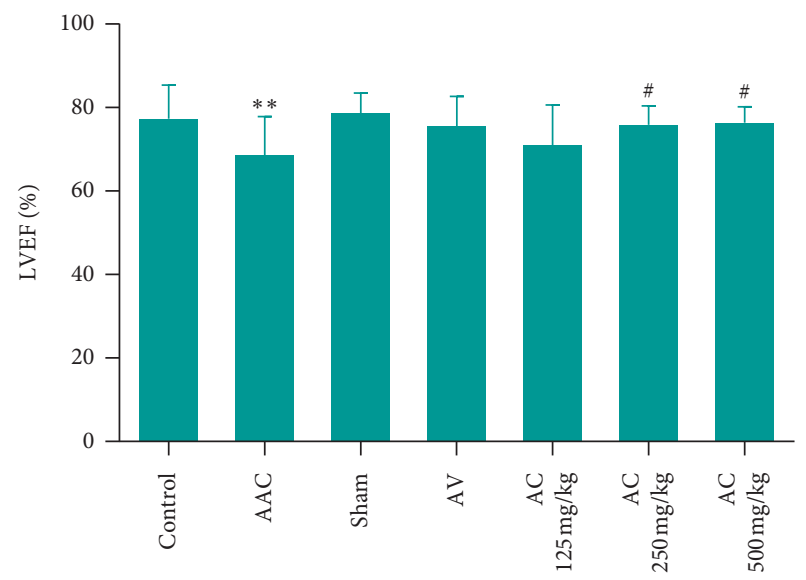

(c)

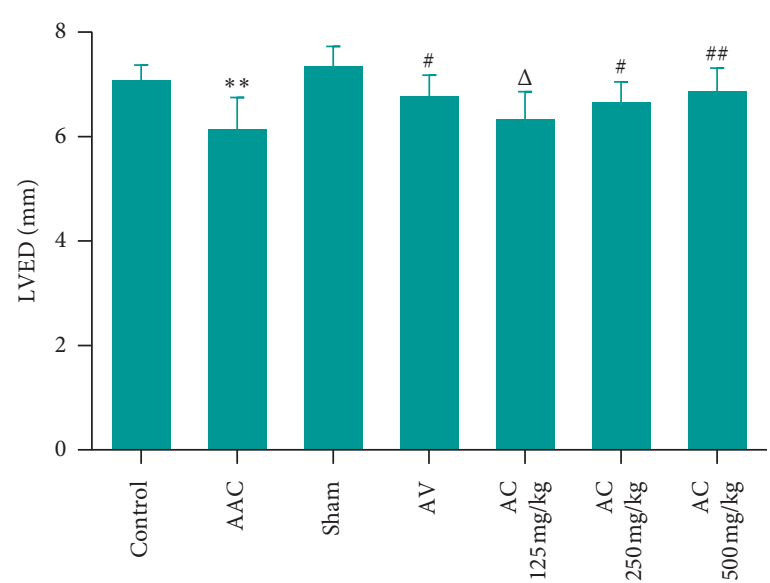

(b)

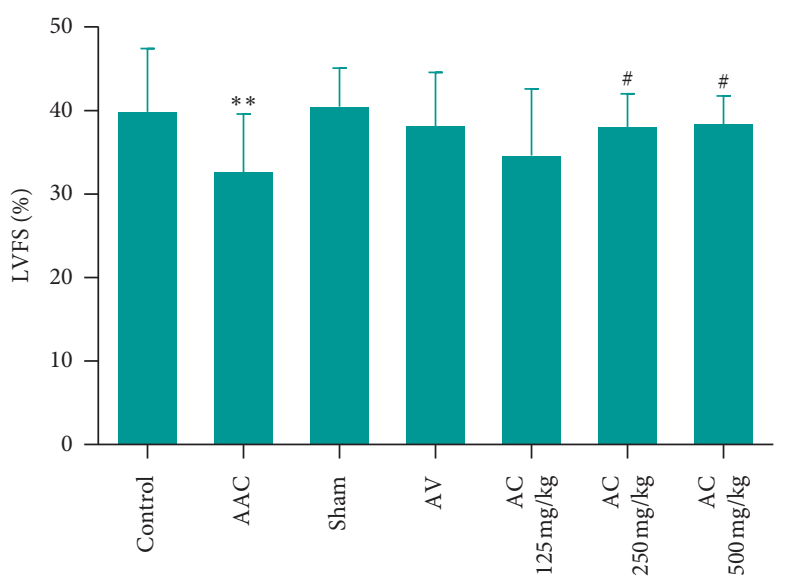

(d)

FIGURE 2: Effects of CPhGs on cardiac ultrasound parameters in rats after AAC: (a) left ventricular posterior wall thickness (LVPWT); (b) left ventricular end-diastolic diameter (LVED); (c) left ventricular ejection fractions (LVEF); and (d) left ventricular fractional shortening (LVFS). ${ }^{* *} p<0.01$ versus sham; ${ }^{\#} p<0.05$, ${ }^{\# \#} p<0.01$ versus AAC; ${ }^{\Delta} P<0.05$ versus AV $(n=9-10)$.

and $500 \mathrm{mg} / \mathrm{kg}$ groups were decreased significantly. The expression levels in AC 500 group were not significantly different compared to those in AV group.

\subsection{CPhGs Reduced the Proinflammatory Factors in Plasma of} Rats after $A A C$. Plasma levels of proinflammatory factors such as COX-1, IL-6, IL-1, and TNF- $\alpha$ of rats in each group were determined. As shown in Figure 5, compared with sham group, the four proinflammatory factors in AAC group were significantly increased. Compared with the AAC group, the proinflammatory factors in each CPhGs dose group decreased significantly, except for TNF- $\alpha$ (5D) of AC125 mg/kg groups. Compared with the AV group, the levels of COX-1, IL-6, and IL- $1 \beta$ in plasma of the AC $500 \mathrm{mg} / \mathrm{kg}$ group showed no significant difference (5ABC); however the levels of TNF- $\alpha$ in plasma of the AC $500 \mathrm{mg} / \mathrm{kg}$ group were lower than those in the AV group. Therefore, CPhGs may have a better effect on reducing proinflammatory factors in rats with cardiac hypertrophy after AAC surgery.

3.5. CPhGs Reduced the Expression of Inflammatory Proteins in Myocardial Tissue of Rats after AAC. The inflammatory response also plays an important role in the pathological 

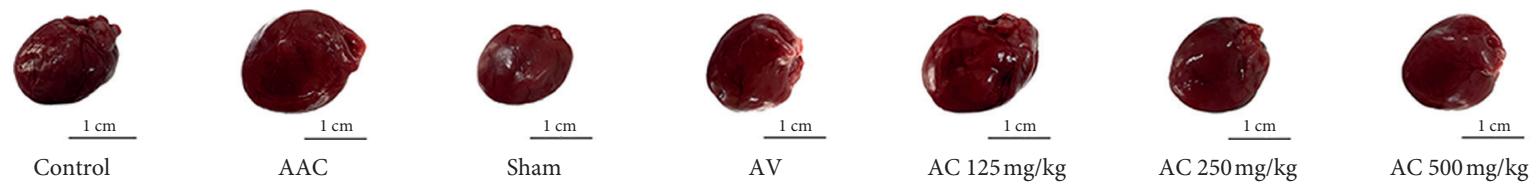

(a)

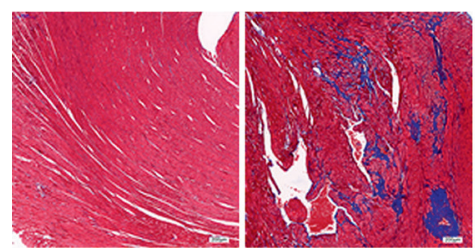

Control

AAC

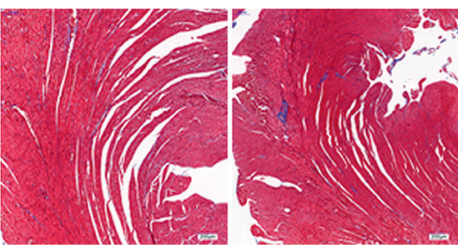

Sham

AV

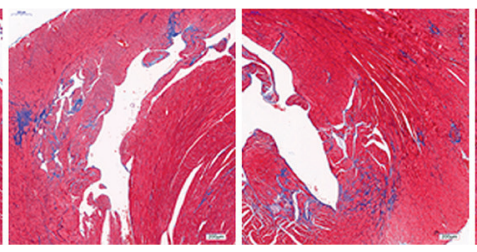

AC $125 \mathrm{mg} / \mathrm{kg}$
AC $250 \mathrm{mg} / \mathrm{kg}$

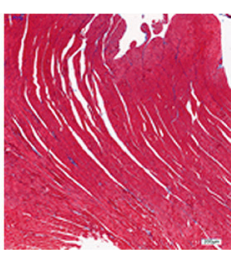

AC $500 \mathrm{mg} / \mathrm{kg}$

(b)

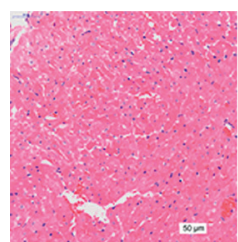

Control

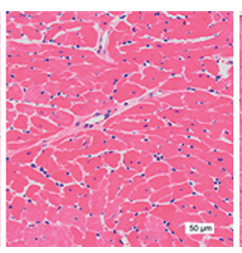

AAC

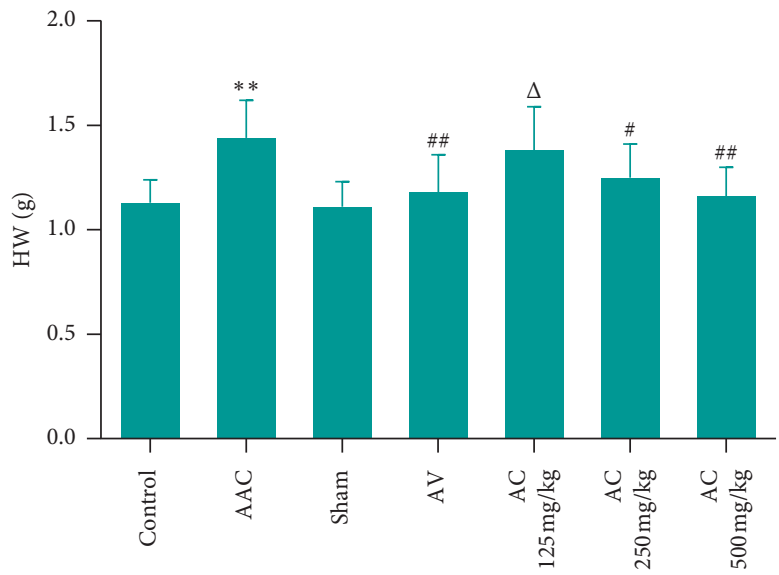

(d)

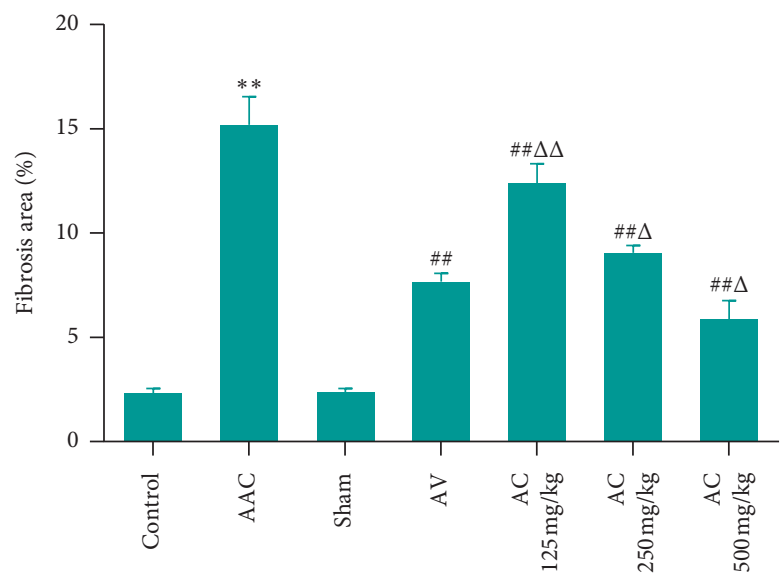

(f)

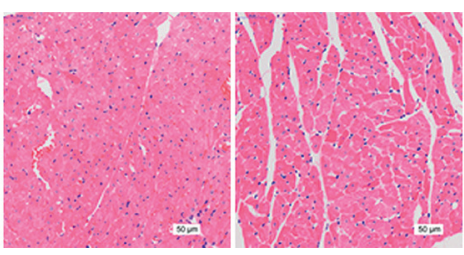

AV

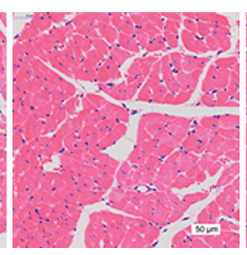

AC $125 \mathrm{mg} / \mathrm{kg}$

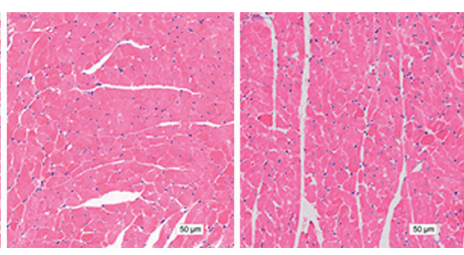

AC $250 \mathrm{mg} / \mathrm{kg}$
AC $500 \mathrm{mg} / \mathrm{kg}$

(c)

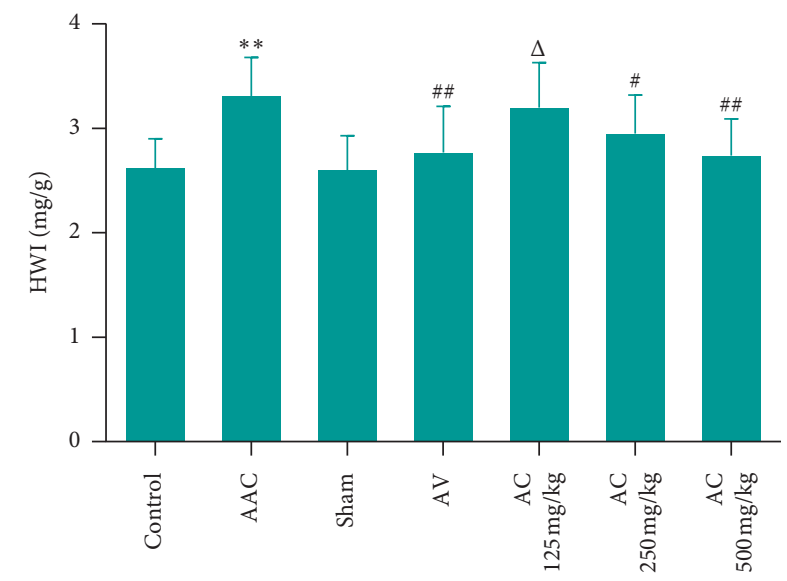

(e)

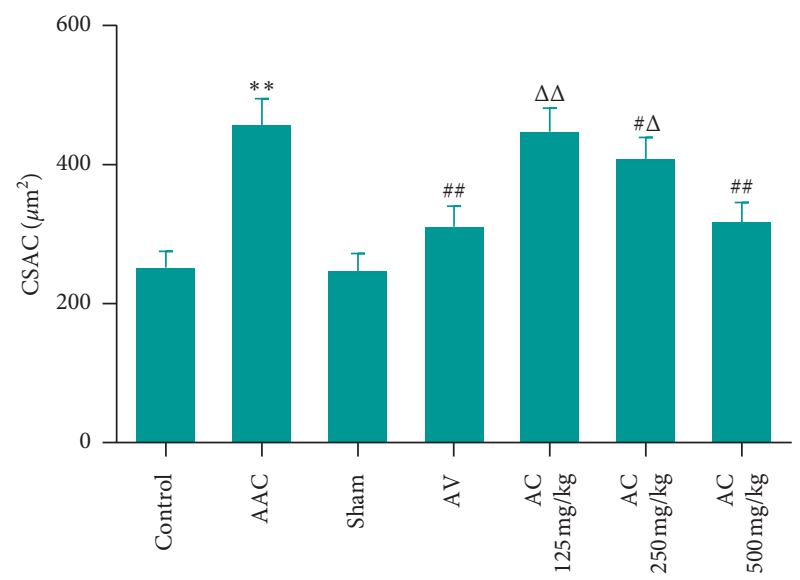

(g)

Figure 3: Effects of CPhGs on HWI, CSAC, and fibrosis area in rats after AAC. (a) Heart shape, bar = $1 \mathrm{~cm}$; (b) masson staining of rat myocardium, bar $=200 \mu \mathrm{m}$; and (c) HE staining of rat myocardium, bar $=50 \mu \mathrm{m}$; (d-g) heart weight (HW), heart weight index (HWI), fibrosis area, and cross-sectional area of cardiomyocytes (CSAC). ${ }^{* *} P<0.01$ versus sham; ${ }^{\#} P<0.05,{ }^{\#} P<0.01$ versus AAC; ${ }^{\Delta} P<0.05$, ${ }^{\Delta \Delta} P<0.01$ versus $\operatorname{AV}(n=9-10)$. 


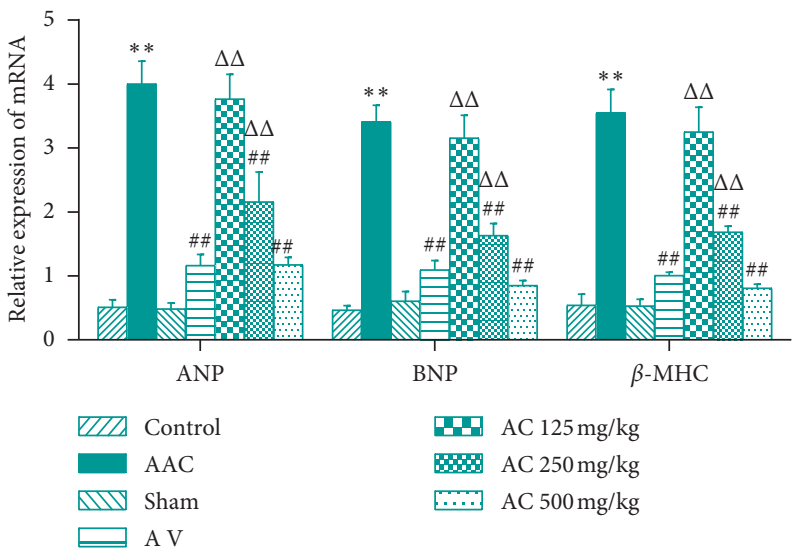

FIGURE 4: Effect of $\mathrm{CPhGs}$ on the expression of myocardial hypertrophy gene mRNA in myocardial tissue of rats after AAC. ${ }^{* *} P<0.01$ versus sham; ${ }^{\# \#} P<0.01$ versus $\mathrm{AAC} ;{ }^{\Delta \Delta} P<0.01$ versus $\mathrm{AV}(n=9-10)$.

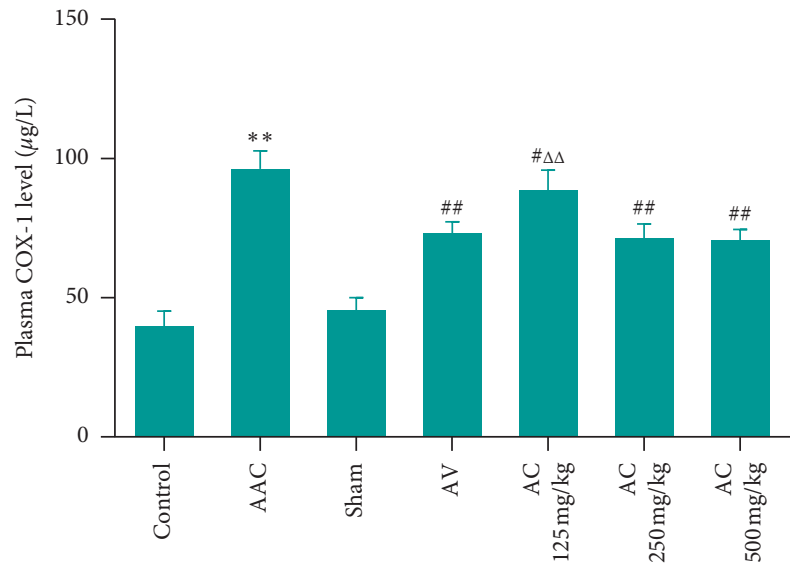

(a)

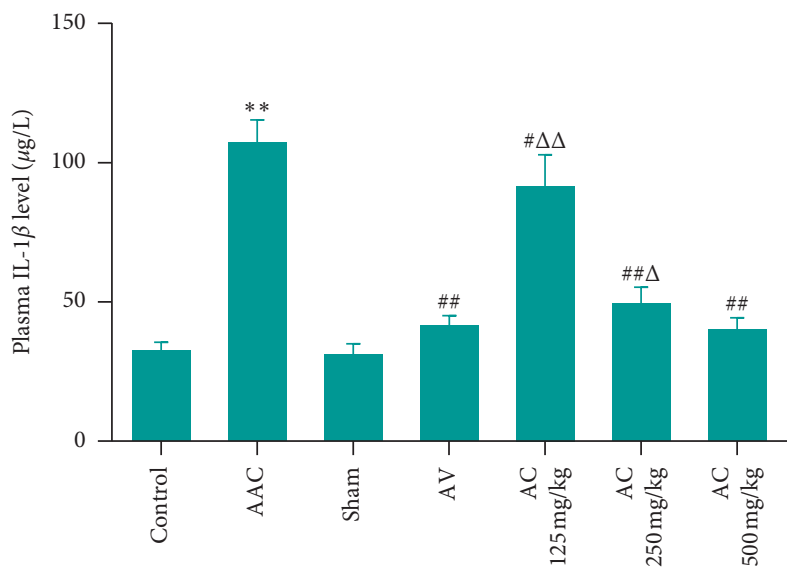

(c)

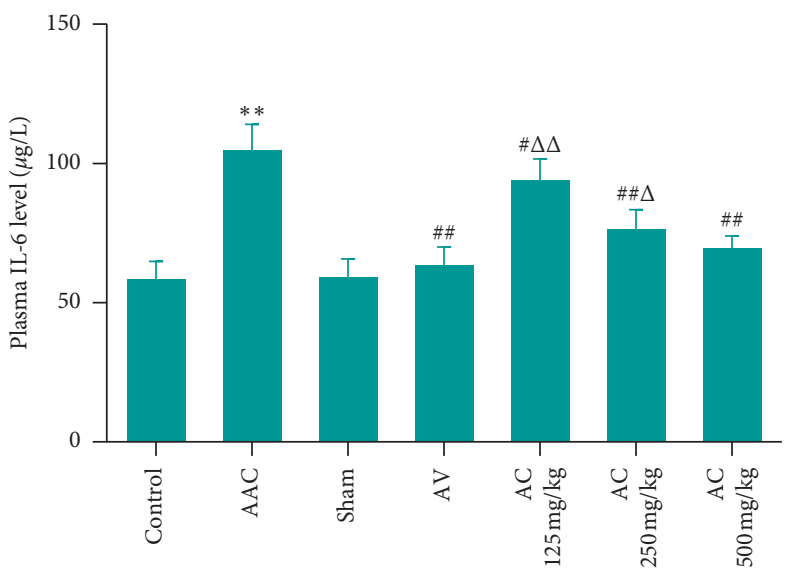

(b)

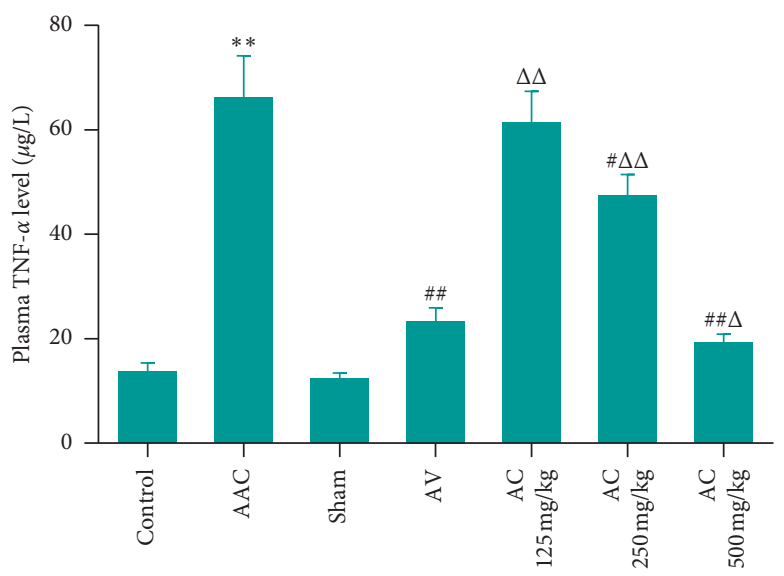

(d)

Figure 5: Effect of CPhGs on proinflammatory factor levels in plasma of rats after AAC. (a) Cyclooxygenase 1 (COX-1); (b) interleukin 6 (IL-6); (c) interleukin $1 \beta$ (IL-1 $\beta$ ); and (d) tumor necrosis factor $\alpha$ (TNF- $\alpha$ ). ${ }^{* *} P<0.01$ versus sham. ${ }^{* *} P<0.01$ versus sham. ${ }^{\#} P<0.01$, ${ }^{\# \#} P<0.01$ versus AAC. ${ }^{\Delta} P<0.01,{ }^{\Delta \Delta} P<0.01$ versus AV $(n=9-10)$.

process of myocardial hypertrophy $[21,22]$. We detected the relative expression levels of cyclooxygenase 2 (COX-2) and high mobility group protein $\mathrm{B} 1$ (HMGB-1) in rat myocardial tissues by western blot. As shown in Figure 6, compared with sham group, the relative expression levels of COX-2 and HMGB-1 protein group were increased significantly in AAC; meanwhile, compared with AAC group, they were reduced significantly in AC 250 and $500 \mathrm{mg} / \mathrm{kg}$ groups. For 


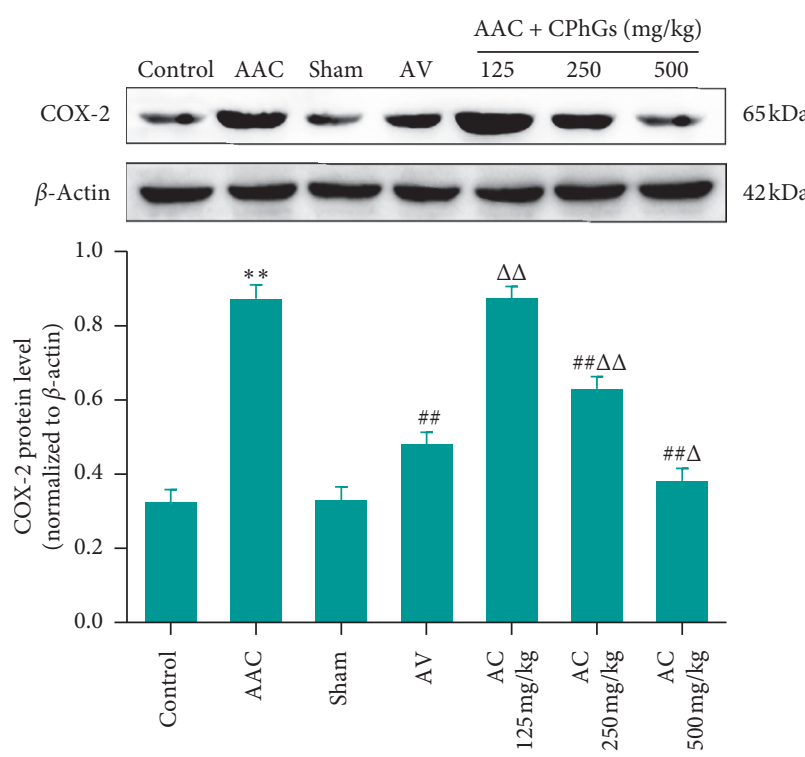

(a)

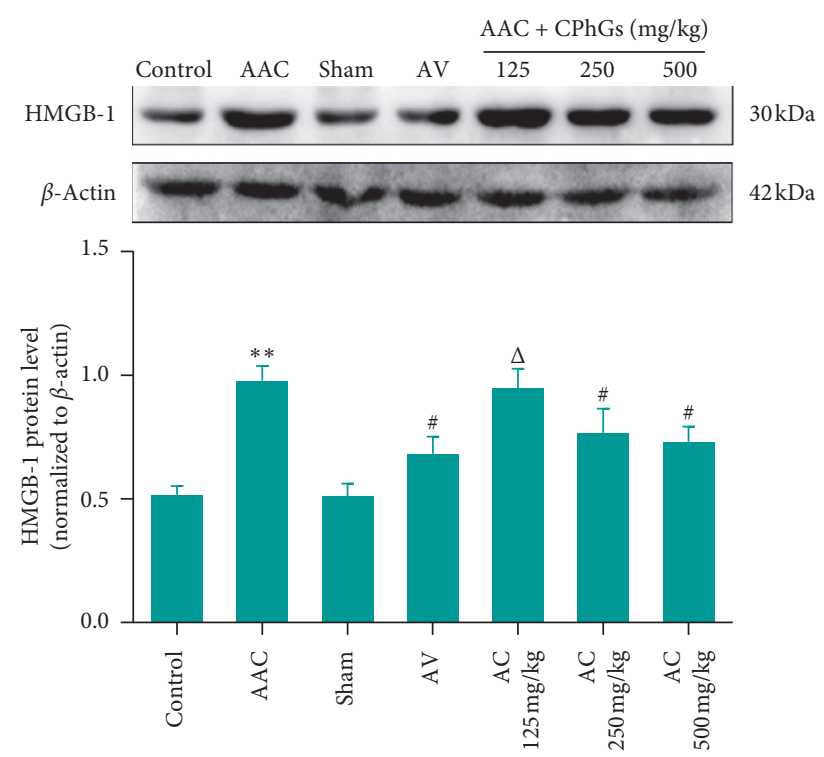

(b)

Figure 6: Effects of CPhGs on the expression of COX-2 and HMGB-1 proteins in myocardial tissues of rats after AAC. (a) Cyclooxygenase 2 (COX-2) and (b) high mobility group protein B1 (HMGB-1). ${ }^{* *} P<0.01$ versus sham. ${ }^{\#} P<0.05$. ${ }^{\# \#} P<0.01$ versus AAC. ${ }^{\triangle} P<0.05$, ${ }^{\Delta \Delta} P<0.01$ versus AV $(n=6)$.

the relative protein expression level of COX-2, it was significantly higher in AC 125 and $250 \mathrm{mg} / \mathrm{kg}$ groups but significantly lower in AC $500 \mathrm{mg} / \mathrm{kg}$ group than that in AV group. For the relative expression level of HMGB1 protein, compared with AV group, it presented a significantly upward tendency in AC $125 \mathrm{mg} / \mathrm{kg}$ group and no significant difference in AC 250 and $500 \mathrm{mg} / \mathrm{kg}$ groups was found.

3.6. CPhGs Reduced the Demethylation Level of ECE-1 in Myocardial Tissue of Rats after AAC. In previous study, we found that ECE-1 demethylation worked on hypertension and might have effect on the production of ET-1 [13]. Accordingly, we wondered whether $\mathrm{CPhGs}$ would affect the demethylation level of ECE-1. As shown in Figure 7, compared with sham group, the methylation level of the ECE-1 in the myocardial tissue was increased significantly in the AAC group. At the same time, it was reduced significantly in AC 125,250 , and $500 \mathrm{mg} / \mathrm{kg}$ groups compared with AAC group. The level of ECE-1 gene demethylation in AC $125 \mathrm{mg} / \mathrm{kg}$ group was significantly higher than that in AV group; there was no significant difference in AC $125 \mathrm{mg} / \mathrm{kg}$ group, but a significant drop was found in AC $500 \mathrm{mg} / \mathrm{kg}$ group when compared to $\mathrm{AV}$ group.

\subsection{CPhGs Decreased the Expression of ECE-1 in Myocardial} Tissue of Rats after AAC. To further understand the effect of ECE-1 methylation, we detected the expression of mRNA, protein, and immunohistochemistry of ECE-1 in myocardial tissue. As shown in Figure 8, compared with sham group, the relative expression levels of ECE-1 mRNA, relative expression levels of protein, and the average area of myocardial immunohistochemistry were reduced significantly in AAC group. Figure $8(\mathrm{c})$ reveals that, compared with the AAC group, the relative expression levels of ECE-1 mRNA were reduced significantly in AC 250 and $500 \mathrm{mg} / \mathrm{kg}$ groups; when compared to the AV group, they were significantly higher in AC 125 and $250 \mathrm{mg} / \mathrm{kg}$ groups but were not significantly different in AC $500 \mathrm{mg} / \mathrm{kg}$ group. Meanwhile, as can be seen in Figures 8(a) and 8(b), compared with AAC group, relative expression levels of ECE-1 protein were significantly decreased in the AC 250 and $500 \mathrm{mg} / \mathrm{kg}$ group; however, they were not significantly different in the AC 250 and $500 \mathrm{mg} / \mathrm{kg}$ group compared to those in AV group. Figures 8(d) and 8(e) indicate that, compared with AAC group, the expression area of ECE-1 in the myocardial tissue of rats was reduced significantly in AC 125,250 , and $500 \mathrm{mg} / \mathrm{kg}$ group; however, compared with AV group, it was significantly higher in AC 125 and $250 \mathrm{mg} / \mathrm{kg}$ groups and showed no significant difference in AC500 mg/kg groups.

3.8. CPhGs Reduced the Plasma ET-1 Level in Rats after AAC. We also measured plasma ET-1 levels in rat by ELISA, as shown in Figure 9, compared with sham group, the plasma levels of ET-1 in AAC group were increased significantly. Meanwhile, the plasma levels of ET-1 showed ascending trend in AC $125 \mathrm{mg} / \mathrm{kg}$ group but indicated no significant difference in AC 250 and $500 \mathrm{mg} / \mathrm{kg}$ groups when compared to those in AV group.

3.9. CPhGs Increased the Expression of PI3K/PKB/eNOS Pathway in Rats after AAC. PI3K/PKB/eNOS is an important pathway in the process of myocardial hypertrophy and has an important connection with ET-1 [14-16]. Therefore, we further detected the proteins expression levels of PI3K/ $\mathrm{PKB} / \mathrm{eNOS}$ pathway in rat myocardial tissue. As shown in Figure 10, compared with sham group, the relative 


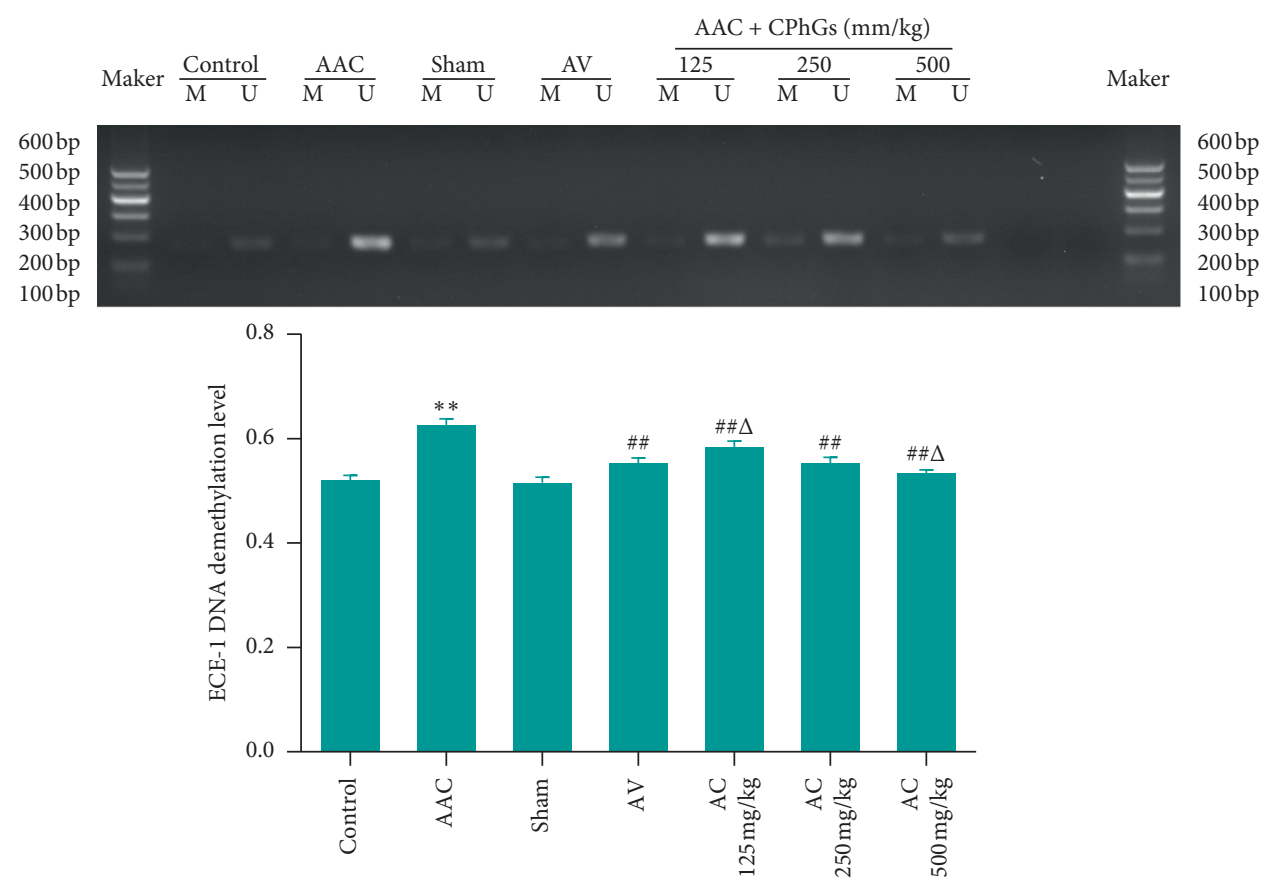

FIGURE 7: Effect of CPhGs on the demethylation level of ECE-1 gene in myocardial tissue of rats after AAC. M: means methylation level, U: means demethylation level. ${ }^{* *} P<0.01$ versus sham, ${ }^{\#} P<0.05$, ${ }^{\# \#} P<0.01$ versus AAC, and ${ }^{\Delta} P<0.05$ versus AV ( $\left.n=6\right)$.

expression levels of $\mathrm{p}-\mathrm{PI} 3 \mathrm{~K}, \mathrm{p}-\mathrm{PKB}$, and $\mathrm{p}$-eNOS proteins in AAC group were reduced significantly; however compared with AAC group, the relative expression levels of p-PI3K were increased significantly in AC 250 and $500 \mathrm{mg} / \mathrm{kg}$ groups. At the same time, the relative expression levels showed a descending trend in AC $125 \mathrm{mg} / \mathrm{kg}$ group and showed no significant difference in AC 250 and $500 \mathrm{mg} / \mathrm{kg}$ groups compared to those in $\mathrm{AV}$ group. As shown in Figure 10(b), compared with AAC group, the relative expression levels of p-PKB were increased significantly in AC 250 and $500 \mathrm{mg} / \mathrm{kg}$ group. Meanwhile, they were significantly lower in AC $125 \mathrm{mg} / \mathrm{kg}$ group and were not significantly different in AC 250 and $500 \mathrm{mg} / \mathrm{kg}$ groups compared to those in AV group. As shown in Figure 10(c), compared with AAC group, the relative expression levels of p-eNOS were increased significantly in AC 125,250 , and $500 \mathrm{mg} / \mathrm{kg}$ groups; however, compared with AV group, the relative expression levels presented a significantly downward trend in AC 125 and $250 \mathrm{mg} / \mathrm{kg}$ groups but showed no significant difference in AC $500 \mathrm{mg} / \mathrm{kg}$ group.

\section{Discussion}

Compared with hypertension patients, those with hypertension and cardiac hypertrophy have a 6-8 times increased probability of acute myocardial infarction, chronic heart failure, and even sudden cardiac death, which seriously affects the treatment and prognosis of hypertension [23, 24]. Under such circumstance, the treatment of hypertension should not be limited to the control of blood pressure. Accordingly, the reversal of cardiac hypertrophy, as the key factor, also deserves great concern. In patients with cardiac hypertrophy, cardiomyocyte protein synthesis is increased in number, enlarged in size, thickened in cell walls, together with the occurrence of more sarcomere, interstitial fibroblast proliferation, and cardiac collagen proliferation. At the same time, the expression of cardiac hypertrophy markers, such as ANP, BNP, and $\beta$-MHC mRNA, is also increased [25-27].

As a traditional Chinese medicine for the treatment of female infertility and male impotence, the stem of Cistanche tubulosa was first recorded in the Shen Nong's Materia Medica in ca. 100 B.C. and is currently widely used as a kind of healthy food in the Southeast Asia area [28]. In recent years, Cistanche tubulosa has drawn the attention of the medical community because of its significant biological activity. As a traditional antifatigue herb, not only Cistanche tubulosa has the function of muscle protection, but also its extract can improve ATP storage and reduce muscle damage after exercise in rats [29]. According to the results of ex vivo experiments, Cistanche tubulosa also has a protective effect against statin-induced muscle toxicity with the help of caspase pathway [30]. In addition, researchers have studied the pharmacological effects of Cistanche tubulosa a in protecting cardiovascular and other aspects and found that Cistanche tubulosa could inhibit the increase of fasting blood glucose and postprandial blood glucose, improve insulin resistance, and ameliorate dyslipidemia, as well as inhibiting weight loss in $\mathrm{db} / \mathrm{db}$ mice [31]. Previous studies showed that $\mathrm{CPhGs}$ can reduce the damage of free radicals to myocardial mitochondrial membrane and plasma omentum, reduce malondialdehyde content, reduce myocardial ultrastructural damage, increase myocardial mitochondrial antioxidant enzyme activity, reduce myocardial infarct size, improve the activity of phosphocreatine in myocardial tissue, and have a protective effect on ischemic myocardium $[9,10,32]$. We aimed to explore the effects of CPhGs on pressure overload- 


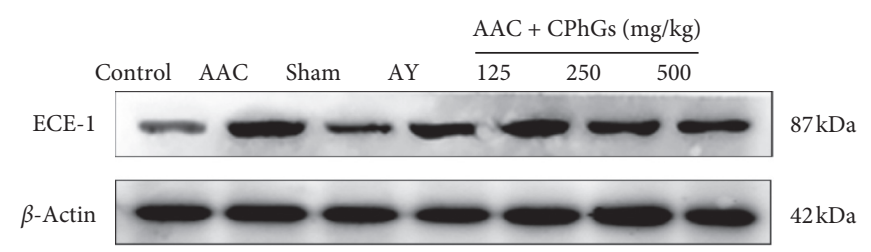

(a)

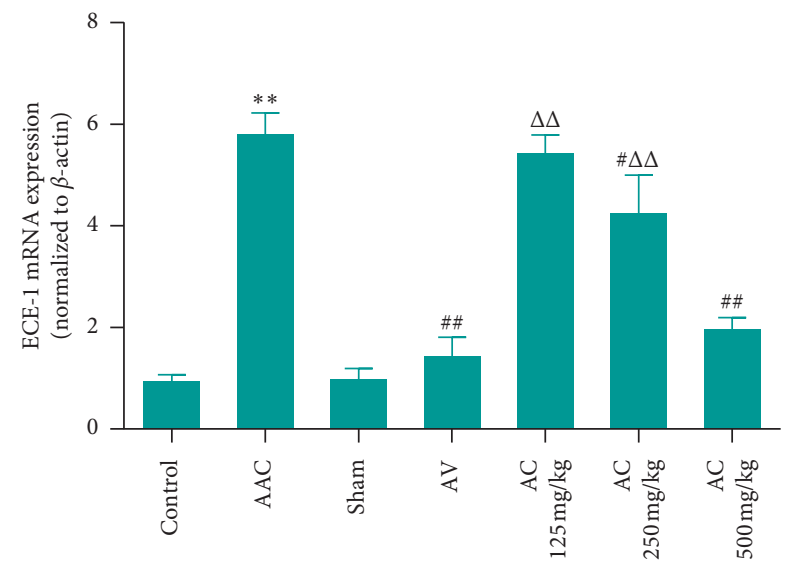

(c)

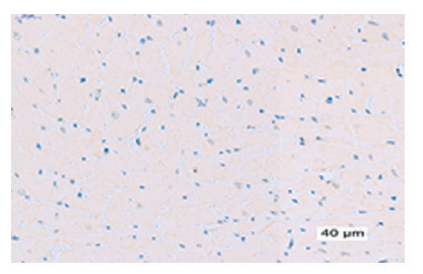

Control

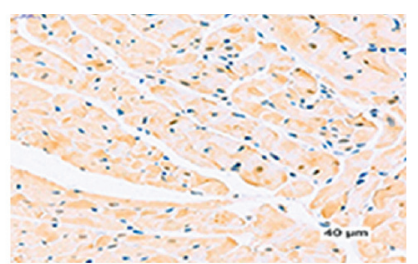

AAC

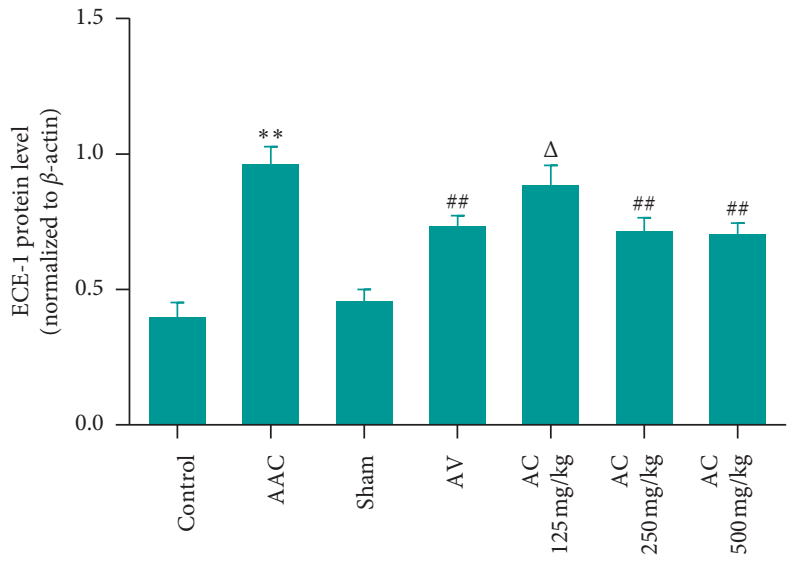

(b)

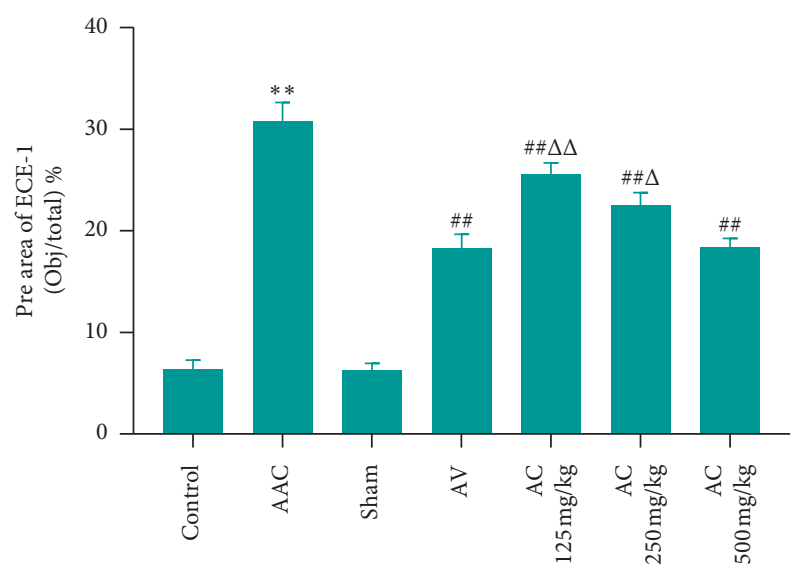

(d)

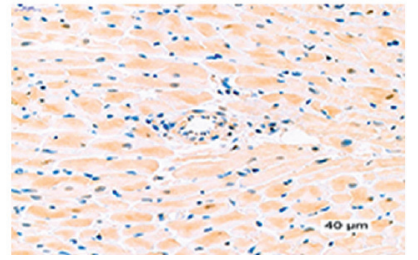

AC $125 \mathrm{mg} / \mathrm{kg}$

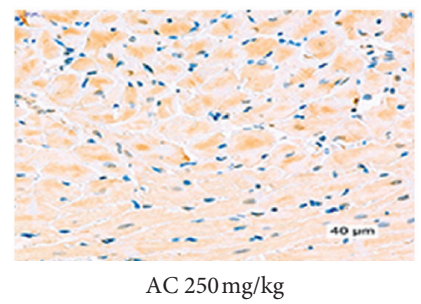

(e)

FIGURE 8: Effect of CPhGs on the expression of ECE-1 in myocardial tissue of rats after AAC. (a), (b) ECE-1 protein level; (c) ECE-1 mRNA expression; and (d), (e) immunohistochemistry of ECE-1 in myocardial tissue. Bar $=20 \mu \mathrm{m} .{ }^{* *} P<0.01$ versus sham; ${ }^{\#} P<0.05$, ${ }^{\# \#} P<0.01$ versus AAC; ${ }^{\Delta} P<0.05,{ }^{\Delta \Delta} P<0.01$ versus AV. $(n=6)$.

induced cardiac hypertrophy. In this study, it was found that CPhGs decreased LVPWT, LVED, HWI, AMC, and cardiac hypertrophy gene levels (i.e., ANP, BNP, and $\beta$-MHC), increased EF and FS, inhibited cardiac hypertrophy, and improved cardiac function in rats. Besides, inflammation is one of the key phenotypes in the pathogenesis of cardiac hypertrophy [33]. Some scholars had found that deletion of IL-6 might attenuate pressure overload-induced left ventricular hypertrophy and dysfunction [34]. And we found that $\mathrm{CPhGs}$ could not only decrease the plasma IL-6 level of rats after $\mathrm{AAC}$, but also reduce other proinflammatory, such as COX-1, IL- $1 \beta$, and TNF- $\alpha$. In addition, CPhGs can also reduce 


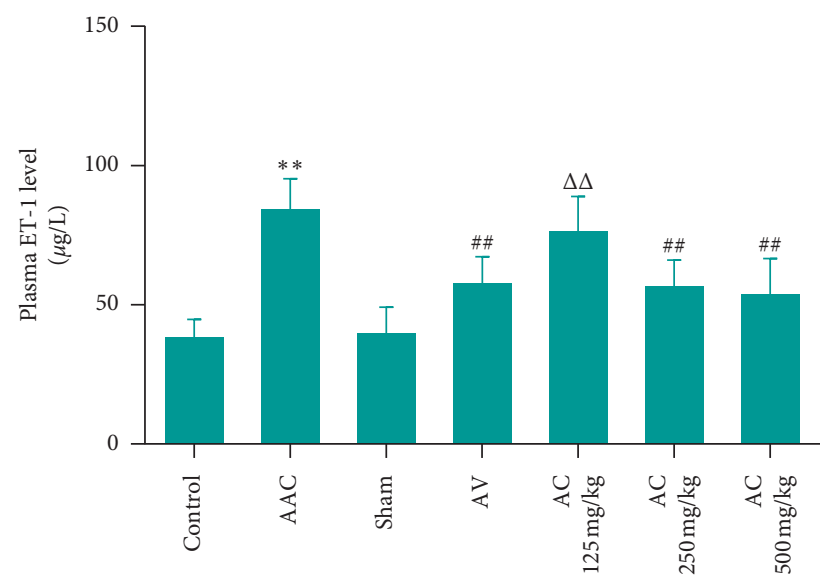

FIGURe 9: Effect of CPhGs on plasma ET-1 levels in rats after AAC. ${ }^{* *} P<0.01$ versus sham, ${ }^{\# \#} P<0.01$ versus AAC, ${ }^{\Delta \Delta} P<0.01$ versus AV $(n=9-10)$.
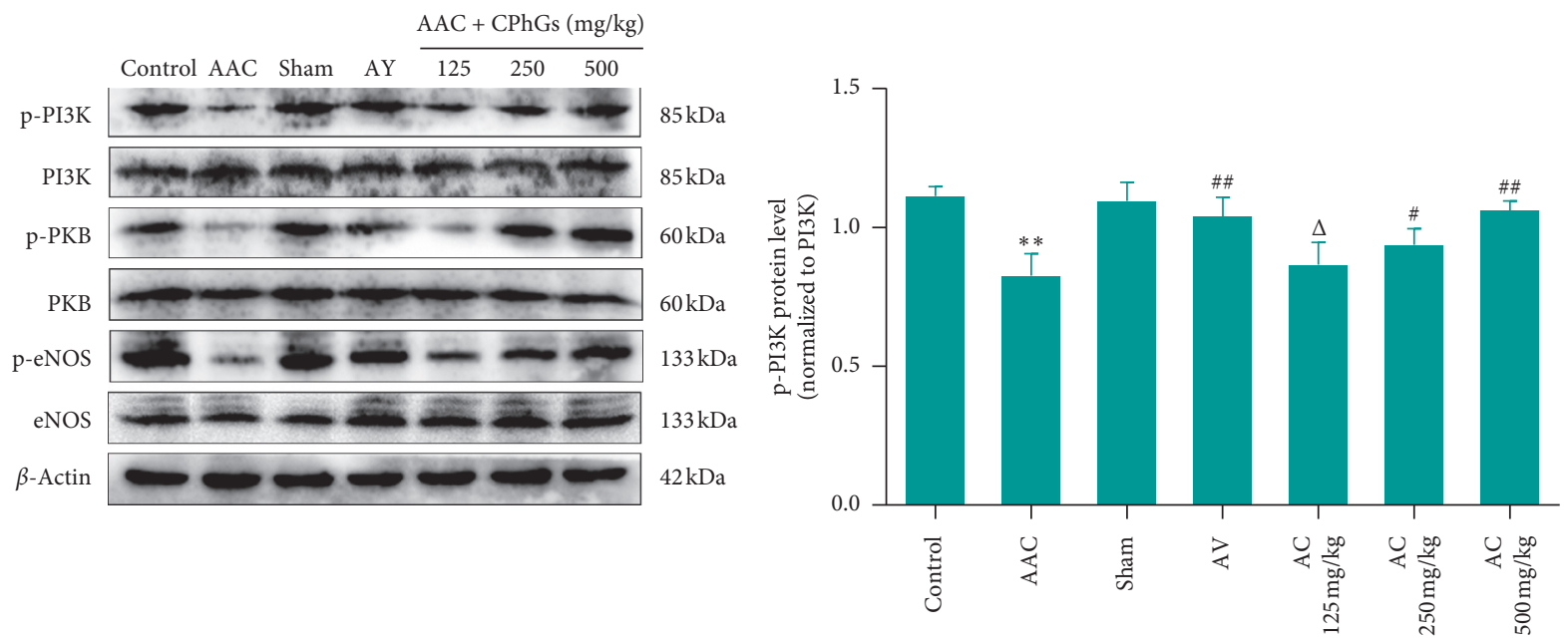

(a)

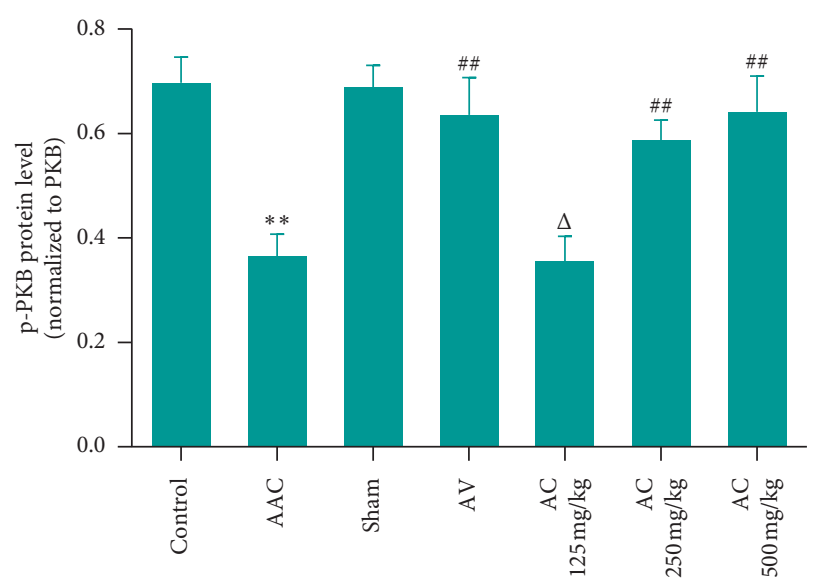

(b)

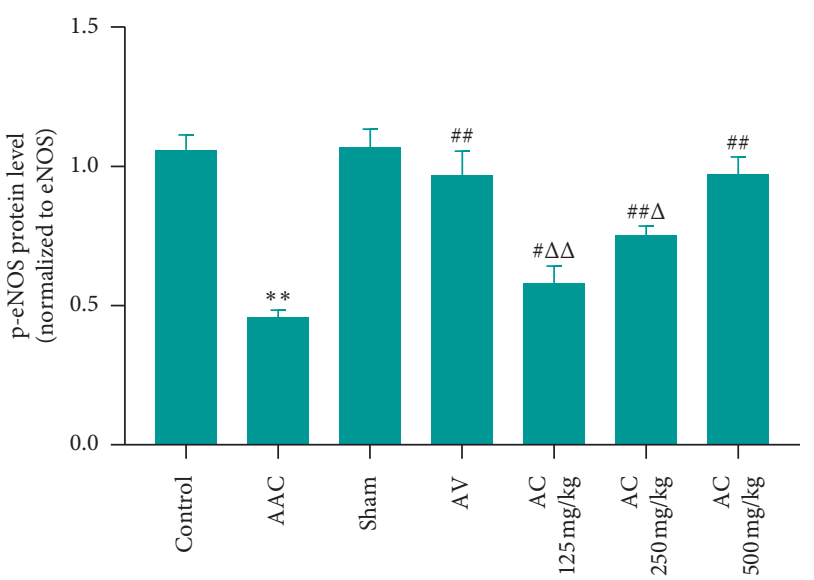

(c)

FIGURE 10: Effect of CPhGs on the expression of PI3K/PKB/eNOS pathway in myocardial tissue of rats after AAC. (a) p-PI3K protein level; (b) p-PKB protein level; and (c) p-eNOS protein level. ${ }^{* *} P<0.01$ versus sham, ${ }^{\#} P<0.05,{ }^{\# \#} P<0.01$ versus AAC, ${ }^{\Delta} P<0.05$ versus AV. $(n=6)$. 
COX-2 and HMGB-1 protein related to inflammation. The effects of $\mathrm{CPhGs}$ were dose-dependent with increasing drug doses. Moreover, it is worth mentioning that the high dose of $\mathrm{CPhGs}$ group had a significant protective effect on hypertrophic rats, similar to the effect of valsartan positive group. Therefore, $\mathrm{CPhGs}$ could be a potential pharmacological agent to inhibit pressure overload-induced cardiac hypertrophy.

DNA methylation refers to a molecular DNA methylation modification process in which S-adenosyl-L-methionine acts as a methyl donor to obtain a methyl group through covalent bonding under the catalysis of DNA methyltransferases [35]. It is well known that ET-1 is the most potent vasoconstrictor and can strongly constrict medullary and medullary arteries, resulting in decreased natriuresis and increased blood pressure [36-38]. Being the key enzyme in the final step of endothelin production, ECE1 not only coexists with ET-1 in cardiovascular diseases, but also can regulate ET-1 production. Thus, ECE-1 can be rather essential to the development and progression of the disease [39]. In in vitro experiments on vascular endothelial cells, methylation of the CpG island in the ECE-1c promoter region decreases its transcriptional activity, resulting in decreased expression of ECE-1c, further leading to decreased production of ET-1 and decreased blood pressure in vivo, and this line of changes suggests that ECE-1 methylation may be involved in the pathology of hypertension $[40,41]$. In our previous study, we also have found increased demethylation of ECE-1 in hypertensive patients [35]. The results of the present study showed that CPhGs significantly reduced ECE-1 demethylation, decreased ECE-1 mRNA and protein expression, and reduced plasma ET-1 levels in the myocardium of rats with pressure overload-induced cardiac hypertrophy after AAC.

Whether CPhGs affect ECE-1 demethylation levels and whether they protect against cardiac hypertrophy in rats have not been clarified. PI3K is the final pathway for cardiomyocyte hypertrophy from contractile to hypertrophic type [42]. Both isoforms of PI3K can be involved in cardiomyocyte hypertrophy, in which $\mathrm{Pll} 0 \alpha$ is involved in physiological hypertrophy, while $\mathrm{p} 110 \gamma$ is involved in pathological hypertrophy. P110, when knocked out in mice, can protect against cardiomyopathic pathological stimuli and plays a crucial role in the development and progression of cardiomyocyte hypertrophy [43]. PKB is central to this signaling pathway. Its activation can modulate molecular function by activating or inhibiting downstream effector molecules through phosphorylation [44]. PI3K/PKB is also a key signaling pathway behind ET-1, and studies have shown that ET-1 can independently induce fibroblast resistance to apoptosis through PI3K/PKB signaling activation [45]. Other studies have shown that ET-1 can regulate the activity of eNOS and the release of NO through endothelin receptor B1 [46]. As an important vasodilator, NO can antagonize the vasoconstrictive effects of ET-1 from multiple levels and maintain normal cardiovascular function [47]. In this study, the middle and high dose CPhGs groups showed a significant increase in $\mathrm{p}$-PI3K, p-PKB, and p-ENOS. However, the high dose CPhGs group had the same effect as AV group, which further demonstrated that CPhGs could inhibit cardiac hypertrophy in rats after AAC by activating the $\mathrm{PI} 3 \mathrm{~K} / \mathrm{PKB} / \mathrm{eNOS}$ signaling pathway. Other studies have also found a link between the PI3K/PKB pathway and inflammatory responses $[48,49]$. Zou and other researchers have reported that in asthma, Brahman-related genes play an essential role in maintaining airway inflammation and affecting the PI3K/Akt/mTOR pathway [50]. In addition, $\mathrm{CPhGs}$ also decreased the expression of inflammation-related genes in myocardial tissue. Therefore, we speculated that $\mathrm{CPhGs}$ may attenuate the inflammatory response in stress-overloaded rats by increasing the PI3K/PKB/eNOS signaling pathway.

Overall, our study is the first to demonstrate the protective effect of CPhGs on pressure overload-induced cardiac hypertrophy in rats after AAC, which may be related to the role CPhGs play in effectively reducing the demethylation level of ECE-1 and enhancing the PI3K/PKB pathway. This finding provides a new idea for the clinical research of hypertension hypertrophy and the development of new therapeutic drugs to prevent, control, and reverse hypertension hypertrophy. Although there are still many key questions waiting to be addressed, further understanding of the mechanisms by which CPhGs and PI3K/PKB mediate inflammatory responses may shed new light on exploring cardiac hypertrophy treatment in the future.

\section{Conclusions}

Our results showed that CPhGs ameliorated myocardial hypertrophy rats by AAC, which may be related to ECE-1 demethylation inhibition and PI3K/PKB/eNOS enhancement.

\section{Data Availability}

All data included in this study are available upon request by contact with the corresponding author.

\section{Conflicts of Interest}

The authors declare no conflicts of interest.

\section{Authors' Contributions}

Shu-Ping You, Tao Liu, Jun Zhao, and Qiong-Ling Fan conceived and designed the experiments. Qiong-Ling Fan, Jia-Wei Wang, and Shi-Lei Zhang worked for methodology. Qiong-Ling Fan, Jia-Wei Wang, Shi-Lei Zhang, and ShuPing You analysed the data. Qiong-Ling Fan, Jia-Wei Wang, and Shi-Lei Zhang wrote the manuscript. Shu-Ping You, Tao Liu, and Jun Zhao reviewed the manuscript. All of the authors read and approved the final manuscript.

\section{Acknowledgments}

This work was funded by a major project of National Key Laboratory Jointly Established by the Provincial and Ministry in Xinjiang Uyghur Autonomous Region (SKLHIDCA-2018-3), National Natural Science Foundation of China (no. 8156140127), and a youth project of Natural 
Science Research in Xinjiang Uyghur Autonomous Region Higher Education Institution (XJEDU2019Y027).

\section{References}

[1] R. E. Katholi and D. M. Couri, "Left ventricular hypertrophy: major risk factor in patients with hypertension: update and practical clinical applications," International Journal of $\mathrm{Hy}$ pertension, vol. 2011, Article ID 495349, 10 pages, 2011.

[2] E. D. Frohlich, "Left ventricular hypertrophy: a major factor of risk in Black hypertensive patients," American Journal of Hypertension, vol. 27, no. 1, pp. 1-2, 2014.

[3] T. M. Okwuosa, E. Z. Soliman, F. Lopez, K. A. Williams, A. Alonso, and K. C. Ferdinand, "Left ventricular hypertrophy and cardiovascular disease risk prediction and reclassification in blacks and whites: the atherosclerosis risk in communities study," American Heart Journal, vol. 169, no. 1, pp. 155-161 e5, 2015.

[4] P. M. Okin, R. B. Devereux, K. E. Harris et al., "In-treatment resolution or absence of electrocardiographic left ventricular hypertrophy is associated with decreased incidence of newonset diabetes mellitus in hypertensive patients: the losartan intervention for endpoint reduction in hypertension (LIFE) study," Hypertension, vol. 50, no. 5, pp. 984-990, 2007.

[5] M. Salvetti, A. Paini, F. Bertacchini et al., "Changes in left ventricular geometry during antihypertensive treatment," Pharmacological Research, vol. 134, pp. 193-199, 2018.

[6] Y. Ye, H. Gong, X. Wang et al., "Combination treatment with antihypertensive agents enhances the effect of qiliqiangxin on chronic pressure overload-induced cardiac hypertrophy and remodeling in male mice," Journal of Cardiovascular Pharmacology, vol. 65, no. 6, pp. 628-639, 2015.

[7] C. Fu, J. Li, A. Aipire et al., "Cistanche tubulosa phenylethanoid glycosides induce apoptosis in Eca-109 cells via the mitochondria-dependent pathway," Oncology Letters, vol. 17, no. 1, pp. 303-313, 2018.

[8] S. P. You, L. Ma, J. Zhao, S. L. Zhang, and T. Liu, "Phenylethanol glycosides from Cistanche tubulosa suppress hepatic stellate cell activation and block the conduction of signaling pathways in TGF- $\beta 11 /$ smad as potential anti-hepatic fibrosis agents," Molecules, vol. 21, no. 1, p. 102, 2016.

[9] H. S. Wong, N. Chen, P. K. Leong, and K. M. Ko, “ $\beta$-Sitosterol enhances cellular glutathione redox cycling by reactive oxygen species generated from mitochondrial respiration: protection against oxidant injury in H9c2 cells and rat hearts," Phytotherapy Research, vol. 28, no. 7, pp. 999-1006, 2014.

[10] Q. Yu, X. Li, and X. Cao, "Cardioprotective effects of phenylethanoid glycoside-rich extract from cistanche deserticola in ischemia-reperfusion-induced myocardial infarction in rats," Annals of Vascular Surgery, vol. 34, pp. 234-242, 2016.

[11] Y. Y. Han, L. J. Wang, L. Zhang et al., "Association between potassium channel SNPs and essential hypertension in Xinjiang Kazak Chinese patients," Experimental and Therapeutic Medicine, vol. 14, no. 3, pp. 1999-2006, 2017.

[12] L. J. Wang, W. W. Zhang, L. Zhang et al., "Association of connexin gene polymorphism with essential hypertension in Kazak and Han Chinese in Xinjiang, China," Journal of Huazhong University of Science and Technology [Medical Sciences], vol. 37, no. 2, pp. 197-203, 2017.

[13] S. P. You, M. L. Cong, G. H. Ni et al., "Blood screening for DNA methylation sites and construction of aberrant methylation profile in kazak essential hypertensive patients," Chinese General Practice, vol. 20, no. 6, pp. 678-683, 2017.
[14] L. Ba, J. Gao, Y. Chen et al., "Allicin attenuates pathological cardiac hypertrophy by inhibiting autophagy via activation of $\mathrm{PI} 3 \mathrm{~K} / \mathrm{Akt} / \mathrm{mTOR}$ and MAPK/ERK/mTOR signaling pathways," Phytomedicine, vol. 58, Article ID 152765, 2019.

[15] M. Vaiou, E. Pangou, P. Liakos et al., "Endothelin-1 (ET-1) induces resistance to bortezomib in human multiple myeloma cells via a pathway involving the ETB receptor and upregulation of proteasomal activity," Journal of Cancer Research and Clinical Oncology, vol. 142, no. 10, pp. 2141-2158, 2016.

[16] A. P. Davenport, K. A. Hyndman, N. Dhaun et al., "Endothelin," Pharmacological Reviews, vol. 68, no. 2, pp. 357-418, 2016.

[17] S. L. Zhang, L. Ma, J. Zhao et al., "The phenylethanol glycoside liposome inhibits PDGF-induced HSC activation via regulation of the FAK/PI3K/akt signaling pathway," Molecules, vol. 24, no. 18, p. 3282, 2019.

[18] M. Luo, P. P. Chen, L. Yang et al., "Sodium ferulate inhibits myocardial hypertrophy induced by abdominal coarctation in rats: involvement of cardiac PKC and MAPK signaling pathways," Biomedicine \& Pharmacotherapy, vol. 112, Article ID 108735, 2019.

[19] J. E. Camacho Londono, Q. Tian, K. Hammer et al., "A background $\mathrm{Ca} 2+$ entry pathway mediated by TRPC1/TRPC4 is critical for development of pathological cardiac remodelling," European Heart Journal, vol. 36, no. 33, pp. 2257-2266, 2015.

[20] C. T. Hang, J. Yang, P. Han et al., "Chromatin regulation by Brg1 underlies heart muscle development and disease," $\mathrm{Na}$ ture, vol. 466, no. 7302, pp. 62-67, 2010.

[21] L. Zhang, X. Yang, G. Jiang et al., "HMGB1 enhances mechanical stress-induced cardiomyocyte hypertrophy in vitro via the RAGE/ERK1/2 signaling pathway," International Journal of Molecular Medicine, vol. 44, no. 3, pp. 885-892, 2019.

[22] R. N. Willette, M. E. Eybye, A. R. Olzinski et al., "Differential effects of p38 mitogen-activated protein kinase and cyclooxygenase 2 inhibitors in a model of cardiovascular disease," Journal of Pharmacology and Experimental Therapeutics, vol. 330, no. 3, pp. 964-970, 2009.

[23] C. Cook, G. Cole, P. Asaria, R. Jabbour, and D. P. Francis, "The annual global economic burden of heart failure," International Journal of Cardiology, vol. 171, no. 3, pp. 368-376, 2014.

[24] L. H. Lindholm, H. Ibsen, B. Dahlof et al., "Cardiovascular morbidity and mortality in patients with diabetes in the losartan intervention for endpoint reduction in hypertension study (LIFE): a randomised trial against atenolol," The Lancet, vol. 359, no. 9311, pp. 1004-1010, 2002.

[25] N. Froese, H. Wang, C. Zwadlo et al., "Anti-androgenic therapy with finasteride improves cardiac function, attenuates remodeling and reverts pathologic gene-expression after myocardial infarction in mice," Journal of Molecular and Cellular Cardiology, vol. 122, pp. 114-124, 2018.

[26] M. Nakamura and J. Sadoshima, "Mechanisms of physiological and pathological cardiac hypertrophy," Nature Reviews Cardiology, vol. 15, no. 7, pp. 387-407, 2018.

[27] Y. Sun, C. Chen, R. Xue et al., "Maf1 ameliorates cardiac hypertrophy by inhibiting RNA polymerase III through ERK1/2," Theranostics, vol. 9, no. 24, pp. 7268-7281, 2019.

[28] H. M. Shi, J. Wang, M. Y. Wang, P. F. Tu, and X. B. Li, "Identification of Cistanche species by chemical and intersimple sequence repeat fingerprinting," Biological and Pharmaceutical Bulletin, vol. 32, no. 1, pp. 142-146, 2009.

[29] R. L. Cai, M. H. Yang, Y. Shi, J. Chen, Y. C. Li, and Y. Qi, "Antifatigue activity of phenylethanoid-rich extract from 
Cistanche deserticola," Phytotherapy Research, vol. 24, no. 2, pp. 313-315, 2009.

[30] E. Wat, C. F. Ng, C. M. Koon, E. C. Wong, B. Tomlinson, and C. B. Lau, "The protective effect of herba cistanches on statininduced myotoxicity in vitro," Journal of Ethnopharmacology, vol. 190, pp. 68-73, 2016.

[31] W. T. Xiong, L. Gu, C. Wang, H. X. Sun, and X. Liu, "Antihyperglycemic and hypolipidemic effects of Cistanche tubulosa in type 2 diabetic $\mathrm{db} / \mathrm{db}$ mice," Journal of Ethnopharmacology, vol. 150, no. 3, pp. 935-945, 2013.

[32] H. S. Wong and K. M. Ko, "Herba Cistanches stimulates cellular glutathione redox cycling by reactive oxygen species generated from mitochondrial respiration in $\mathrm{H} 9 \mathrm{c} 2$ cardiomyocytes," Pharmaceutical Biology, vol. 51, no. 1, pp. 64-73, 2013.

[33] F. Jaffre, J. Callebert, A. Sarre et al., "Involvement of the serotonin 5-HT2B receptor in cardiac hypertrophy linked to sympathetic stimulation," Circulation, vol. 110, no. 8, pp. 969-974, 2004.

[34] L. Zhao, G. Cheng, R. Jin et al., "Deletion of interleukin-6 attenuates pressure overload-induced left ventricular hypertrophy and dysfunction," Circulation Research, vol. 118, no. 12, pp. 1918-1929, 2020.

[35] T. B. Miranda and P. A. Jones, "DNA methylation: the nuts and bolts of repression," Journal of Cellular Physiology, vol. 213, no. 2, pp. 384-390, 2007.

[36] S. C. Coelho, O. Berillo, A. Caillon et al., "Three-month endothelial human endothelin-1 overexpression causes blood pressure elevation and vascular and kidney injury," Hypertension, vol. 71, no. 1, pp. 208-216, 2018.

[37] N. Dhaun, R. Moorhouse, I. M. MacIntyre et al., "Diurnal variation in blood pressure and arterial stiffness in chronic kidney disease," Hypertension, vol. 64, no. 2, pp. 296-304, 2014.

[38] M. Subramanian, S. M. MohanKumar, P. Balasubramanian et al., "Chronic exposure to low doses of estradiol-17 $\beta$ increases blood pressure in young female rats: a possible role for central Endothelin-1," Scientific Reports, vol. 7, no. 1, p. 139, 2017.

[39] S. Friso, F. Pizzolo, S. W. Choi et al., "Epigenetic control of 11 beta-hydroxysteroid dehydrogenase 2 gene promoter is related to human hypertension," Atherosclerosis, vol. 199, no. 2, pp. 323-327, 2008 .

[40] H. Funke-Kaiser, F. Reichenberger, K. Kopke et al., "Differential binding of transcription factor E2F-2 to the endothelinconverting enzyme-1b promoter affects blood pressure regulation," Human Molecular Genetics, vol. 12, no. 4, pp. 423433, 2003.

[41] H. Funke-Kaiser, A. Thomas, J. Bremer et al., "Regulation of the major isoform of human endothelin-converting enzyme-1 by a strong housekeeping promoter modulated by polymorphic microsatellites," Journal of Hypertension, vol. 21, no. 11, pp. 2111-2124, 2003.

[42] W. Qian, D. Yu, J. Zhang et al., "Wogonin attenuates isoprenaline-induced myocardial hypertrophy in mice by suppressing the PI3K/akt pathway," Frontiers in Pharmacology, vol. 9, p. 896, 2018.

[43] M. Shao, C. Zhuo, R. Jiang et al., "Protective effect of hydrogen sulphide against myocardial hypertrophy in mice," Oncotarget, vol. 8, no. 14, pp. 22344-22352, 2017.

[44] Y. Gu, R. Cai, C. Zhang et al., "miR-132-3p boosts caveolaemediated transcellular transport in glioma endothelial cells by targeting PTEN/PI3K/PKB/Src/Cav-1 signaling pathway," The FASEB Journal, vol. 33, no. 1, pp. 441-454, 2019.
[45] P. Kulasekaran, C. A. Scavone, D. S. Rogers, D. A. Arenberg, V. J. Thannickal, and J. C. Horowitz, "Endothelin-1 and transforming growth factor- $\beta 1$ independently induce fibroblast resistance to apoptosis via AKT activation," American Journal of Respiratory Cell and Molecular Biology, vol. 41, no. 4, pp. 484-493, 2009.

[46] S. H. Tsai, G. Lu, X. Xu, Y. Ren, T. W. Hein, and L. Kuo, "Enhanced endothelin-1/Rho-kinase signalling and coronary microvascular dysfunction in hypertensive myocardial hypertrophy," Cardiovascular Research, vol. 113, no. 11, pp. 1329-1337, 2017.

[47] R. M. Rapoport, "Acute nitric oxide synthase inhibition and endothelin-1-dependent arterial pressure elevation," Frontiers in Pharmacology, vol. 5, p. 57, 2014.

[48] C. C. Huang, C. H. Chiou, S. C. Liu et al., "Melatonin attenuates TNF- $\alpha$ and IL- $1 \beta$ expression in synovial fibroblasts and diminishes cartilage degradation: implications for the treatment of rheumatoid arthritis," Journal of Pineal Research, vol. 66, no. 3, Article ID e12560, 2019.

[49] M. Xiang, T. Liu, W. Tan et al., "Effects of kinsenoside, a potential immunosuppressive drug for autoimmune hepatitis, on dendritic cells/CD8(+) T cells communication in mice," Hepatology, vol. 64, no. 6, pp. 2135-2150, 2016.

[50] W. Zou, F. Ding, C. Niu, Z. Fu, and S. Liu, "Brg1 aggravates airway inflammation in asthma via inhibition of the PI3K/ Akt/mTOR pathway," Biochemical and Biophysical Research Communications, vol. 503, no. 4, pp. 3212-3218, 2018. 